\title{
Application of the acetolactate synthase gene as a cisgenic selectable marker for Agrobacterium-mediated transformation in Chinese cabbage (Brassica rapa ssp. pekinensis)
}

\author{
Ken-ichi Konagaya a, Mai Tsuda, Ayako Okuzaki, Sugihiro Ando ${ }^{\text {b }}$ Yutaka Tabei* \\ National Institute of Agrobiological Sciences, Tsukuba, Ibaraki 305-8602, Japan \\ *E-mail: tabei@affrc.go.jp Tel \& Fax: +81-29-838-8372
}

Received December 12, 2012; accepted January 24, 2013 (Edited by S. Ogita)

\begin{abstract}
Heading Chinese cabbage (Brassica rapa ssp. pekinensis) has been recalcitrant to regeneration and transformation. In particular, there are few reports concerning Japanese cultivars. We evaluated the factors that inhibit Agrobacterium-mediated transformation in heading Chinese cabbage. Then, we investigated the effects of selectable markers using heading Chinese cabbage cv. Chihiri 70 and compared the effects with those in broccoli cv. Ryokurei (B. oleracea var. italica) as a control for an easily transformable Brassica species. To utilize a selectable marker derived from a host plant cisgene, we cloned a genomic DNA fragment containing regulatory and coding sequences of the acetolactate synthase (ALS) gene from Chinese cabbage and mutagenized it to a herbicide resistant form. After transformation of Chinese cabbage and broccoli with this construct, transgenic plants were efficiently selected with the herbicide bispyribac sodium salt and screened by DNA gel blot analysis. The average transformation frequency of Chinese cabbage was $1.2 \pm 0.2 \%$, which was similar to those in reports using antibiotic selectable markers and was lower than for broccoli (13.9 $\pm 2.0 \%)$. Furthermore, the escape rate was restricted at a low level (about 35-50\% lower than hygromycin selection), which is an advantage on practical transformation. We confirmed transgene inheritance and herbicide resistance of potted plants in the $\mathrm{T}_{1}$ generation. This report is the first to describe a selection system for the transformation of a Brassica crop that uses a herbicide-tolerant selectable marker derived from a cisgene.
\end{abstract}

Key words: Acetolactate synthase, Brassica oleracea, Brassica rapa, cisgenic selectable marker, transformation.

The genus Brassica includes highly diverse crops that are grown and bred worldwide. In particular, B. rapa includes various vegetables such as Chinese cabbage, pak choi, turnip, and others. Chinese cabbage (B. rapa ssp. pekinensis) is one of the most important vegetables in Asia and is widely used for traditional fermented pickles and as a cooked vegetable. Although Chinese cabbages are classified as heading, semi-heading, and non-heading types based on the leaf morphology, the heading type accounts for the majority of Japan's Chinese cabbage market.

In August 2011, the Brassica rapa Genome Sequencing Project published a draft genome sequence of Chinese cabbage (Wang et al. 2011). The research group in Japan published 5476 independent full-length cDNA sequences from approximately 10,000 clones (Abe et al. 2011). Since the gene sequences of Chinese cabbage have high similarity (ca. 90\%) with those of the model plant Arabidopsis thaliana (Wang et al. 2011), information obtained using $A$. thaliana can be applied to studies of other plants in the family Brassicaceae. Genetic transformation is an essential tool for using these resources for reverse-genetic studies, molecular breeding, etc. Successful Agrobacterium-mediated transformation of Brassica crops has been reported in B. oleracea, B. rapa, B. napus, B. juncea, and B. carinata (reviewed in: Cardoza and Stewart 2004; Poulsen 1996; Sparrow et al. 2011). In particular, there are many reports of transformation for broccoli (B. oleracea var. italica) using Agrobacterium tumefaciens (Chen et al.

Abbreviations: 2,4-D, 2,4-dichlorophenoxy acetic acid; ALS, acetolactate synthase; BA, 6-benzylamino purine; BrALS3, Brassica rapa acetolactate synthase; BS, bispyribac sodium; GM, genetically modified; GUS, beta-glucuronidase; MS, Murashige and Skoog; NAA, Naphthaleneacetic acid; PCR, Polymerase chain reaction; RFLP, Restriction fragment length polymorphism; TAIL-PCR, thermal asymmetric interlaced PCR; T-DNA, transfer-DNA.

${ }^{a}$ Present address: Forest Bio-Research Center, Forestry and Forest Products Research Institute, Hitachi, Ibaraki 319-1301, Japan.

${ }^{b}$ Present address: Department of Life Science, Graduate School of Agricultural Science, Tohoku University, Sendai, Miyagi 981-8555, Japan.

This article can be found at http://www.jspcmb.jp/

Published online May 22, 2013 
2001; Kuginuki et al. 2001; Metz et al. 1995; Suri et al. 2005), and transgenic broccoli has been subjected to field trials (Waterer et al. 2000). However, B. rapa, especially heading Chinese cabbage, is known as one of the most recalcitrant members of Brassica genus to transformation (Bagheri 2009; Kuginuki et al. 2001; Narasimhulu and Chopra 1988). Thus, it is essential to develop an efficient transformation method to overcome genotype dependency. The recalcitrance of Chinese cabbage to transformation could be due to the low efficiency of Agrobacterium infection, low regeneration efficiency of the infected tissues, and low selection efficiency for transformed cells (Lee et al. 2004; Takasaki et al. 1997). Bacterial antibiotic resistance genes such as $n p t I I$ and $h p t$ (Cho et al. 2001; Jun et al. 1995; Kuginuki et al. 2001; Lee et al. 2004; Park et al. 2005; Shin et al. 2003; Vanjildorj et al 2009; Zhang et al. 2000), herbicide resistance genes such as bar (Lim et al. 2007), and a mannose-6phosphate isomerase gene from Escherichia coli (Min et al. 2007) have been used as selectable markers for Chinese cabbage transformation. However, to date, no plant-derived gene has been used as a selectable marker for Chinese cabbage transformation.

Acetolactate synthase (ALS) catalyzes the first step in the biosynthesis of the essential branched chain amino acids, and it is a target enzyme for a number of herbicides. An amino acid substitution at a particular position in ALS has been shown to confer resistance to herbicides such as sulfonylureas and imidazolinones and to pyrimidinyl carboxy herbicides. Mutant forms of the $A L S$ gene have been reported to be useful as a selectable marker in many plant species, such as potato (Andersson et al. 2003), oilseed mustard (Ray et al. 2004), rice (Okuzaki et al. 2007; Osakabe et al. 2005), maize (Zhang et al. 2005), cotton (Rawat et al. 2008), wheat (Ogawa et al. 2008), and soybean (Tougou et al. 2009). The use of an $A L S$ gene derived from the host crop itself would be expected to result in a more publicly acceptable genetically modified (GM) crop compared with the use of a conventional antibiotic selectable marker.

In the present study, we examined differences in Agrobacerium infectivity and regeneration ability using the Japanese cultivar of heading Chinese cabbage with broccoli as a comparison control representing an easily transformable Brassica species. In addition, we successfully tested the use of a mutated ALS gene derived from Chinese cabbage as an effective in vitro selection marker for heading Chinese cabbage and for broccoli.

\section{Materials and methods}

\section{Plant material}

Chinese cabbage (B. rapa ssp. pekinensis cv. Chihiri 70) and broccoli (B. oleracea var. italica cv. Ryokurei) were used in this study. Hypocotyls were cultured according to Takasaki et al. (1997) and Kuginuki and Tsukazaki (2001) with some modifications. The seeds (Takii Seed Co., Japan) were surface sterilized with sodium hypochlorite solution $(0.5 \%$ active chlorite) plus $0.1 \%$ Tween-20 for $15 \mathrm{~min}$ and then rinsed three times with sterile distilled water. Plant boxes (60 mm $\times 60 \mathrm{~mm} \times 100 \mathrm{~mm}$; AGC Techno Glass Co., Japan) containing $0.8 \%$ agar-solidified MS medium (Murashige and Skoog 1962) were inoculated with 20-30 seeds each. The hypocotyls were excised from 1-week-old seedlings, cut into $7-10 \mathrm{~mm}$ segments, and cultured in $20 \times 90 \mathrm{~mm}$ Petri dishes containing callus induction medium (BCC2 or BCC 3 in the section mentioned below). All cultures were incubated at $22^{\circ} \mathrm{C}$ under a 16-h light/8-h dark photoperiod, except for the cocultivation in the dark. The plates were sealed with surgical tape (Nichiban, Japan).

\section{Isolation of Chinese cabbage ALS gene and vector construction}

Genomic DNA from the leaves of the Chinese cabbage cv. Muso (a common Japanese cultivar, Takii Seed Co.) was extracted using the DNeasy Plant Mini Kit (Qiagen, Germany) according to the manufacturer's instructions. The orthologous fragment of the ALS gene was isolated by polymerase chain reaction (PCR) using KOD-Plus-DNA polymerase (Toyobo, Japan) and the BnALS1F5 and BnALS1(WL)R primers (Table 1) derived from the B. napus gene (GenBank accession number Z11526) in the sequence database. The PCR product was cloned into the pCR-Blunt II-TOPO vector (Invitrogen, USA) and sequenced with an automated DNA sequencer (ABI PRISM 3100; Applied Biosystems, USA) using the BigDye Terminator Cycle Sequencing Kit (v.3.1; Applied Biosystems). The upstream and downstream regions of the Chinese cabbage ALS (BrALS3; GenBank accession number AB618066) fragment were isolated by thermal asymmetric interlaced PCR (TAIL-PCR; Liu et al. 1995) using specific primers (Table 1). The flanking region of the open reading frame (ORF) containing the promoter and terminator was amplified by PCR using specific primers (BrALS-F-Pac and BrALS-R-Sbf) with added restriction sites (Table 1). Double point mutations (Trp556Leu and Ser635Ile) of BrALS3 for herbicide resistance were introduced by sitedirected mutagenesis (Sambrook and Russell 2001). These mutations were matched to the amino acid substitutions in Arabidopsis or rice $A L S$ genes that confer resistance to pyrimidinyl carboxy herbicides including bispyribac sodium (BS) (Kawai et al. 2010; Osakabe et al. 2005), since the positions of the amino acid substitutions involved in herbicide resistance are conserved among plants (Mazur and Falco 1989). The pSMAH-35S: GUS vector (Figure 1A, Konagaya et al. 2008) was constructed by the replacement of the beta-glucuronidase

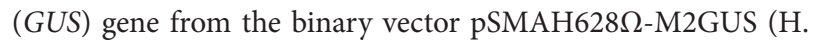
Nakamura et al., in preparation) with the cauliflower mosaic virus (CaMV) $35 \mathrm{~S}$ promoter and Intron-GUS from pIG121-Hm (Ohta et al. 1990). The pSMAA-35S:GUS vector (Figure 1B) was constructed by the replacement of the HPT cassette from pSMAH-35S:GUS with the mutated ALS (BrmALS3) cassette. 
Table 1. Primers used.

\begin{tabular}{|c|c|c|}
\hline Name & Sequence $5^{\prime}-3^{\prime a}$ & Application \\
\hline BnALS1F5 & TTACGCTCGTTCCTCCGGCAAA & PCR for coding region of $B r A L S 3$ \\
\hline BnALS1F6 & CTTGGCATGCACGGGACTGTGT & $\begin{array}{l}\text { Specific primer } 1 \text { for TAIL-PCR for } 5^{\prime} \text { upstream region of } \\
\text { BrALS3 ORF }\end{array}$ \\
\hline $\mathrm{AD} 20$ & NGTCGASWGANAWGAA & $\begin{array}{l}\text { Arbitrary primer for TAIL-PCR for } 5^{\prime} \text { upstream region of } \\
\text { BrALS3 ORF }\end{array}$ \\
\hline BrALS-R3 & GGCGTCTCTTGGAAGGCGTCAGT & $\begin{array}{l}\text { Specific primer } 1 \text { for TAIL-PCR for } 3^{\prime} \text { downstream region of } \\
\text { BrALS3 ORF }\end{array}$ \\
\hline BnALS1R2 & ATCCGGCGAGGGACCTGTCCTG & $\begin{array}{l}\text { Specific primer } 2 \text { for TAIL-PCR for } 3^{\prime} \text { downstream region of } \\
\text { BrALS3 ORF }\end{array}$ \\
\hline BrALS-R4 & GGGACCCGAAGTGGCAATGCAGA & $\begin{array}{l}\text { Specific primer } 3 \text { for TAIL-PCR for } 3^{\prime} \text { downstream region of } \\
\text { BrALS3 ORF }\end{array}$ \\
\hline $\mathrm{AD} 2$ & TCTTICGNACITNGGA & $\begin{array}{l}\text { Arbitrary primer for TAIL-PCR for } 3^{\prime} \text { downstream region of } \\
\text { BrALS3 ORF }\end{array}$ \\
\hline \multirow[t]{2}{*}{ BnALS1(WL)F } & TGGTCATGCAATTGGAAGATCGGTT & $\begin{array}{l}\text { Specific primer } 2 \text { for TAIL-PCR for } 5^{\prime} \text { upstream region of } \\
\text { BrALS3 ORF }\end{array}$ \\
\hline & & Site-directed mutagenesis for BrmALS3 \\
\hline \multirow[t]{3}{*}{ BnALS1(WL)R } & AACCGATCTTCCAATTGCATGACCA & PCR for coding region of $B r A L S 3$ \\
\hline & & $\begin{array}{l}\text { Specific primer } 3 \text { for TAIL-PCR for } 5^{\prime} \text { upstream region of } B r A L S 3 \\
\text { ORF }\end{array}$ \\
\hline & & Site-directed mutagenesis for $B r m A L S 3$ \\
\hline BnALS1(SI)F & TTACCGATGATCCCAATTGGTGGCA & Site-directed mutagenesis for $B r m A L S 3$ \\
\hline BnALS1(SI)R & TGCCACCAATTGGGATCATCGGTAA & Site-directed mutagenesis for $B r m A L S 3$ \\
\hline BrALS-F-Pac & GTTAATTAACTGAAACAATGAGTGTGAAAG & PCR for BrmALS3 cassette ( $P a c \mathrm{I}$ site are underlined) \\
\hline BrALS-R-Sbf & CCTGCAGGATGTTTATTTCAACACAGATGT & PCR for BrmALS3 cassette (Sbfl site are underlined) \\
\hline mGUS-31 & 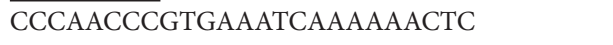 & GUS probe for Southern hybridization \\
\hline $759-\mathrm{L}$ & ATGTTTGAACGATCGGGGAAAT & GUS probe for Southern hybridization \\
\hline Bogai-F10 & ATTACTATTCGACACTGTTTGATTC & Bogai probe for Southern hybridization \\
\hline Bogai-R10 & ATACCACCACCAACCTAGTCTAC & Bogai probe for Southern hybridization \\
\hline BoA3F11oku & GGTGAGAAGTAGAAACCCAACG & PCR for the Bogai gene \\
\hline BoGAIut-R01 & AGAGCTCCACTGATTTTGAAACTCAAACAACC & PCR for the Bogai gene \\
\hline BrALS9oku & GCTTTGCAAGGGATGAACAAGG & PCR for the BrmALS3 gene \\
\hline BrALS-R1866 & GATGACATCCAACAGGTACGG & PCR for the BrmALS3 gene \\
\hline Actin-F & GTGACAATGGAACTGGAATGG & PCR for the $B r A C T 1$ gene \\
\hline Actin-R & AGACGGAGGATAGCGTGAGG & PCR for the $B r A C T 1$ gene \\
\hline
\end{tabular}

${ }^{\mathrm{a}} \mathrm{I}$, Inosine; $\mathrm{N}, \mathrm{A}$ or $\mathrm{C}$ or $\mathrm{G}$ or $\mathrm{T} ; \mathrm{S}, \mathrm{G}$ or $\mathrm{C} ; \mathrm{W}, \mathrm{A}$ or T.

The pSMAA-BoA3:Bogai vector (Figure 1C) was constructed by replacement of the GUS cassette from pSMAA-35S:GUS with the Bogai (Konagaya et al. 2008) cassette derived from a broccoli genome sequence.

\section{Bacterial strains}

Binary vectors were transferred to A. tumefaciens strain GV3101 (Koncz and Schell 1986) by the freeze-thaw method (An et al. 1988). The Agrobacterium cells were cultured overnight at $28^{\circ} \mathrm{C}$ in $50 \mathrm{ml}$ tubes containing liquid Luria broth ( $\mathrm{pH}$ 5.2) supplemented with $25 \mathrm{mgl}^{-1}$ gentamicin, $25 \mathrm{mgl}^{-1}$ rifampicin, $100 \mathrm{mgl}^{-1}$ spectinomycin, $10 \mathrm{mM} \mathrm{MES}$, and $20 \mu \mathrm{M}$ acetosyringone. The Agrobacterium cells were then centrifuged at $13,000 \times g$ for $1 \mathrm{~min}$ and resuspended to $\mathrm{OD}_{600}=0.1$ with liquid cocultivation medium MS-1 (MS salts, $100 \mathrm{mgl}^{-1}$ myoinositol, $1.3 \mathrm{mgl}^{-1}$ thiamine- $\mathrm{HCl}, 200 \mathrm{mgl}^{-1} \mathrm{KH}_{2} \mathrm{PO}_{4}, 1 \mathrm{mgl}^{-1}$ 2,4-D, $10 \mathrm{mM}$ MES, 3\% sucrose, $\mathrm{pH}$ 5.2) supplemented with $200 \mu \mathrm{M}$ acetosyringone. The suspended cells were kept for $2 \mathrm{~h}$ at room temperature to ensure efficient induction of vir genes (Nanasato et al. 2011, 2012).

\section{Transformation}

Hypocotyl explants from the Chinese cabbage cv. Chihiri 70 and the broccoli cv. Ryokurei were precultured on BCC3 [B5 salts and vitamins (Gamborg et al. 1968), 1\% sucrose, 0.4\% gelrite, $\mathrm{pH} 5.8,10 \mathrm{mgl}^{-1}$ 1-naphthaleneacetic acid (NAA)] and BCC2 media (B5 salts and vitamins, $1 \%$ sucrose, $0.4 \%$ gelrite, $\mathrm{pH} 5.8,3 \mathrm{mgl}^{-1} \mathrm{NAA}$ ), respectively, for 3 days. For co-cultivation, hypocotyls were immersed in the bacterial suspension for $30 \mathrm{~min}$, blotted on sterile paper to remove excess Agrobacterium, transferred onto $0.4 \%$ gelrite-solidified MS-1 medium, and cultured for 3 days in the dark. After cocultivation, the explants from the cultivars were rinsed three times with sterile distilled water and cultured on BCC3 and BCC2 media, respectively, supplemented with $200 \mathrm{mgl}^{-1}$ carbenicillin for 7 days to eliminate Agrobacterium and induce calli. Agrobacterium infection efficiency was determined by performing a histochemical assay of transient GUS activity after decolonization and callus induction for 7 days. The cultured explants were transferred to BCR medium (BCR: B5 salts and vitamins, $3 \mathrm{mgl}^{-1}$ 6-benzylamino purine, $1 \mathrm{mgl}^{-1}$ zeatin, $10 \mathrm{mgl}^{-1} \mathrm{AgNO}_{3}, 1 \%$ sucrose, $0.4 \%$ gelrite, $\mathrm{pH}$ 5.8) 

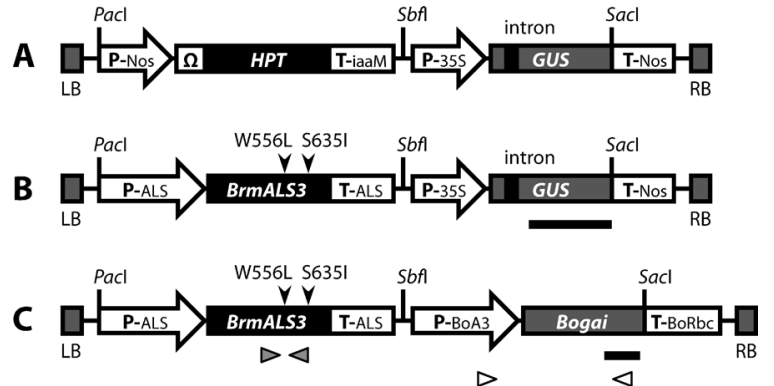

Figure 1. Schematic of the T-DNA region (not to scale) of transformation vector constructs. (A) pSMAH-35S:GUS, (B) pSMAA35S:GUS, and (C) pSMAA-BoA3:Bogai. The vector backbone was pSMAH628 $\Omega$-M2GUS (H. Nakamura et al. in preparation), which contains the spectinomycin resistance gene as a bacterial selectable marker. P-Nos, nopaline synthase promoter; $\Omega$, omega sequence from Tobacco mosaic virus; HPT, hygromycin phosphotransferase gene; T-iaaM, polyadenylation signal from the Agrobacterium iaaM gene; P-35S, CaMV 35S promoter; GUS, beta-glucuronidase gene containing a castor bean intron; T-Nos, nopaline synthase terminator; BrmALS3, mutated acetolactate synthase gene derived from the Brassica rapa ssp. pekinensis cv. Muso gene BrALS3; P-ALS, BrALS3 promoter; T-ALS, BrALS3 terminator; P-BoA3, B. oleracea BoA3 promoter; Bogai, B. oleracea GAI mutant (Konagaya et al. 2008); T-BoRbc, B. oleracea Rubisco terminator (GenBank accession number AB745449); RB, right border; LB, left border. Black arrowheads represent the two mutation sites in BrmALS3: tryptophan to leucine at codon 556 (W556L) and serine to isoleucine at codon 635 (S635I). Open arrowheads and gray arrowheads represent the primer sets for Bogai and BrmALS3 detection, respectively. Black bars indicate the GUS and Bogai probe regions used for DNA gel blot analysis.

supplemented with $200 \mathrm{mgl}^{-1}$ carbenicillin and selective agents (20 $\mathrm{mgl}^{-1}$ hygromycin or $0.25 \mathrm{mgl}^{-1} \mathrm{BS}$; Wako, Japan) and subsequently subcultured every 2 weeks. After 3-4 weeks, calli with green shoots or green calli were transferred to a shoot maturation medium (B5 salts and vitamins, $1 \%$ sucrose, $0.4 \%$ gelrite, $\mathrm{pH}$ 5.8) supplemented with $200 \mathrm{mgl}^{-1}$ carbenicillin and the selective agents. When they reached ca. $2 \mathrm{~cm}$ in height, green shoots were excised from calli and placed on a root induction medium (MS half-salts and vitamins, $1 \mathrm{mgl}^{-1} \mathrm{NAA}$, $1 \%$ sucrose, $0.4 \%$ gelrite, $\mathrm{pH} 5.8$ ) supplemented with $200 \mathrm{mgl}^{-1}$ carbenicillin and the selective agents. After 3 days, the green plantlets were transferred to plant boxes containing $0.4 \%$ gelrite-solidified MS medium supplemented with $200 \mathrm{mgl}^{-1}$ carbenicillin and the selective agents. The leaf segments of green shoots transformed with pSMAA-35S:GUS or pSMAH35S:GUS were tested for GUS expression.

\section{Histochemical GUS assay}

GUS assays were conducted by a modification of a method originally described by Jefferson (1987). Hypocotyls or leaf segments were incubated for $12 \mathrm{~h}$ at $37^{\circ} \mathrm{C}$ in a GUS assay solution containing $100 \mathrm{mM}$ sodium phosphate $(\mathrm{pH} 7.0$ ), $0.3 \%$ Triton $\mathrm{X}-100,0.5 \mathrm{mM}$ potassium ferrocyanide, $0.5 \mathrm{mM}$ potassium ferricyanide, $20 \%$ methanol, and $1 \mathrm{mM} 5$-bromo-4chloro-3-indolyl- $\beta$-D-glucuronide (X-gluc). The stained tissues were bleached by several changes of $70 \%$ ethanol.

\section{DNA gel blot and PCR analyses}

Genomic DNA from Chinese cabbage and broccoli were isolated as described by Ando et al. (2005). DNA ( $5 \mu \mathrm{g})$ was digested with HindIII or XbaI. The digest was fractionated on a $0.9 \%$ agarose gel and transferred to a GeneScreen Plus membrane (PerkinElmer Life and Analytical Sciences) according to the manufacturer's instructions. The GUS and Bogai probes were prepared by PCR (amplified regions in Figure 1) using the primer sets mGUS-31/759-L and Bogai-F10/Bogai-R10, respectively (Table 1). Primer labeling, hybridization, and successive washings were performed as described by Ando et al. (2005). PCR was performed with KOD-Plus-DNA polymerase and gene specific primers. The PCR primer pairs (Table 1, Figure 1) were as follows: BoA3F11oku and BoGAIut-R01 for the Bogai gene, BrALS9oku and BrALS-R1866 for the BrALS3 and BrmALS3 genes, and Actin-F and Actin-R for the actin gene (BrACT1; GenBank accession number AJ242531). Cycling conditions were $94^{\circ} \mathrm{C}$ for $2 \mathrm{~min}$; 35 cycles of $94^{\circ} \mathrm{C}$ for $30 \mathrm{~s}, 62^{\circ} \mathrm{C}$ for $15 \mathrm{~s}$, and $68^{\circ} \mathrm{C}$ for $2 \mathrm{~min}$; and a 10 -min final extension at $68^{\circ} \mathrm{C}$. To confirm the BrmALS3 gene at the molecular level, we performed PCR restriction fragment length polymorphism (PCR-RFLP) analysis with $M f e I$ digestion (Osakabe et al. 2005), since the introduction of the mutations produced two new $M f e I$ sites in the BrALS3 gene (Supplemental Figure S2).

\section{BS herbicide treatment of $T_{1}$ progeny}

The primary transgenic plants were vernalized at $4^{\circ} \mathrm{C}$ for approximately 1 month. Selfed progeny were then recovered by bud pollination. $\mathrm{T}_{1}$ seeds were sown in petri dishes on watersaturated filter paper and incubated under continuous light at $27^{\circ} \mathrm{C}$ for 2 days. Germinated seeds were transferred into pots $(6 \mathrm{~cm}$ diameter) with standard soil and cultivated in a growth chamber at $21^{\circ} \mathrm{C}$ under a 16 -h light/8-h dark photoperiod. Seedlings were screened by PCR for the inheritance of the transgene. After 12 days of incubation, $25 \mathrm{~g}$ a.i. $\mathrm{ha}^{-1} \mathrm{BS}$ solution were sprayed over the leaves of the transgenic Chinese cabbage every other day for two weeks, and the growth of the herbicidetreated plants was assessed.

\section{Results and discussion}

\section{Infectivity of Agrobacterium in Chinese cabbage and broccoli}

Regeneration, as well as transformation, is difficult with B. rapa compared with B. oleracea, as described by Kuginuki et al. (2001). The difficulty in transforming B. rapa has been considered to be due to the low Agrobacterium infection efficiency and low regeneration efficiency of the infected tissues (Takasaki et al. 1997). To identify differences in Agrobacterium infectivity between Chinese cabbage (B. rapa) and, broccoli ( $B$. oleracea) we investigated infection efficiency by transient GUS expression in hypocotyls. Broccoli hypocotyls exhibited an infection efficiency of $61.2 \%$. In contrast, 
Chinese cabbage showed significantly higher infection frequencies of $99.2 \%$ (Figure 2, Table 2). Moreover, both the size and the number of blue spots on the cut ends of hypocotyls were considerably larger than in broccoli (Figure 2). The same result was obtained with the B. rapa variants Ryokusai No. 1 and Marubakomatsuna (data not shown). These results indicate that Agrobacterium infection efficiency of $B$. rapa is higher than that of broccoli, at least among the cultivars examined in this study. Consequently, difficulties in transforming $B$. rapa is thought to be because of low shoot regeneration

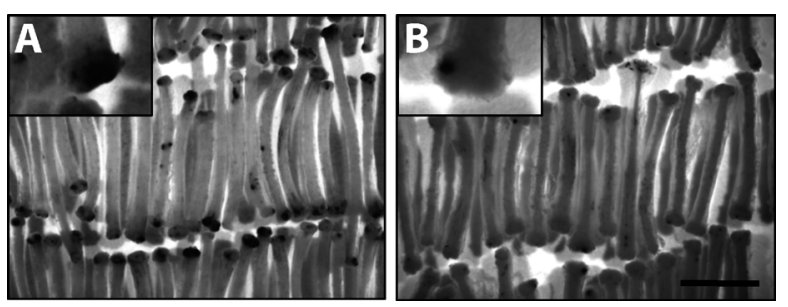

Figure 2. Histochemical detection of GUS activity in hypocotyls. (A) Chinese cabbage cv. Chihiri 70; (B) broccoli cv. Ryokurei. Hypocotyl segments of 7-day-old seedlings were cocultivated for 3 days with Agrobacterium harboring pSMAA-35S:GUS. Chihiri 70 was then cultured on BCC 3 medium and Ryokurei was cultured on BCC2 medium for one week. The number of GUS-positive spots was significantly higher in Chihiri 70 explants (A) compared with Ryokurei explants (B). The inset shows a $3 \times$ magnified image of GUS-positive spots observed in the cut end of a hypocotyl segment. Bar, $5 \mathrm{~mm}$.

Table 2. Agrobacterium infection frequency of Chinese cabbage cv. Chihiri 70 and broccoli cv. Ryokurei.

\begin{tabular}{|c|c|c|}
\hline & Chihiri 70 & Ryokurei \\
\hline No. of infected explants & 122 & 533 \\
\hline $\begin{array}{l}\text { No. of GUS-positive } \\
\text { explants }\end{array}$ & 121 & 326 \\
\hline Infection frequency $(\%)^{a}$ & 99.2 & 61.2 \\
\hline
\end{tabular}

${ }^{\mathrm{a}}$ Infection frequency $(\%)=($ no. of GUS-positive explants/no. of infected explants $) \times 100$. A significant difference between Chihiri 70 and Ryokurei was found by Tukey's multiple comparison test $(p<0.001)$. efficiency or insufficient selection efficiency by antibiotics (e.g., kanamycin or hygromycin).

\section{Comparisons of selectable marker genes}

From our results described above, regeneration efficiency from explants should be important for efficient transformation of Chinese cabbage. Chihiri 70 was used in our experiment because Chihiri 70 has been reported as a cultivar with high regeneration ability from cotyledonary explants (Zhang et al. 1998) and the ability was also confirmed by our preliminary regeneration test (Supplemental Figure S1) using hypocotyl explants. In addition, the shoot regeneration efficiency of Chihiri 70 in the optimal callus induction medium was comparable to that of broccoli (Supplemental Figure S1). On the other hand, improvement of selection efficiency should be also crucial points to examine the efficient transformation of $B$. rapa. For transformant selection, we tested the BrmALS3 (binary vector pSMAA-35S:GUS) and $h p t$ (binary vector pSMAH-35S:GUS) genes conferring resistance to BS and hygromycin, respectively. Transformants were obtained from all combinations of Brassica species and selection agents, and transformation frequency showed same efficiency between BS and hygromycin in both Brassica species (Table 3).

In Chihiri 70, Agrobacterium-infected hypocotyl explants showed green calli and shoot buds on cut ends of hypocotyls within 5 weeks when incubated in BCR medium containing BS or hygromycin for selection (Figure 3A). Each of the green calli or shoot buds regenerated 2-4 multiple shoots when cultured on shoot maturation medium for 30-45 days (Figure 3B). After cultivation on root induction medium for 3 days, regenerated shoots were transferred to hormone-free solid MS medium led to the formation of rooted plantlets within 20-30 days (Figure 3C). Histochemical GUS assays of the leaves from transformed lines exhibited characteristic blue color after incubation in X-gluc

Table 3. Transformation frequencies for Chinese cabbage cv. Chihiri 70 and broccoli cv. Ryokurei with $0.25 \mathrm{mgl}^{-1}$ bispyribac sodium (BS) and $20 \mathrm{mgl}^{-1}$ hygromycin as the selection agents. BCC3 and BCC2 were used for callus induction in Chihiri 70 and Ryokurei, respectively.

\begin{tabular}{|c|c|c|c|c|}
\hline & \multicolumn{2}{|c|}{ Chihiri 70} & \multicolumn{2}{|c|}{ Ryokurei } \\
\hline & BS & Hygromycin & BS & Hygromycin \\
\hline Total no. of infected explants & 1320 & 1020 & 180 & 180 \\
\hline Total no. of green callia & 425 & 583 & 175 & 352 \\
\hline Total no. of green shoots ${ }^{\mathrm{b}}$ & 22 & 21 & 29 & 39 \\
\hline Total no. of elongated plants ${ }^{c}$ & 15 & 11 & 25 & 29 \\
\hline Total no. of transformed plants ${ }^{\mathrm{d}}$ & 15 & 11 & 25 & 27 \\
\hline Total no. of escape shoots ${ }^{\mathrm{e}}$ & 7 & 10 & 4 & 12 \\
\hline Transformation frequency $(\%)^{\mathrm{f}, \mathrm{h}}$ & $1.2 \pm 0.2$ & $1.1 \pm 0.1$ & $13.9 \pm 2.0$ & $15.0 \pm 1.7$ \\
\hline Escape shoot inducing frequency $(\%)^{g, h}$ & $27.7 \pm 15.2$ & $42.9 \pm 14.3$ & $14.4 \pm 7.5$ & $29.8 \pm 6.8$ \\
\hline
\end{tabular}

${ }^{\mathrm{a}}$ Green callus produced on BCR medium containing the selective agent. ${ }^{\mathrm{b}}$ Green shoots produced on shoot maturation medium containing the selective agent; each shoot was from an independent transformation event. ' Shoots elongated and rooted on hormone-free MS medium containing the selective agent. ${ }^{\mathrm{d}}$ Determined by detection of GUS gene by DNA gel blot analysis. ${ }^{\mathrm{e}}$ No. of escape shoots $=$ no. of green shoots - no. of transformed plants. ${ }^{\mathrm{f}}$ Transformation frequency $(\%)=($ no. of transformed plants/no. of infected explants $) \times 100 .{ }^{\mathrm{g}}$ Escape shoot induction frequency $(\%)=($ no. of escape shoot/no. of green shoots $) \times 100 .{ }^{\mathrm{h}}$ Data are mean values \pm standard errors from three independent experiments. 

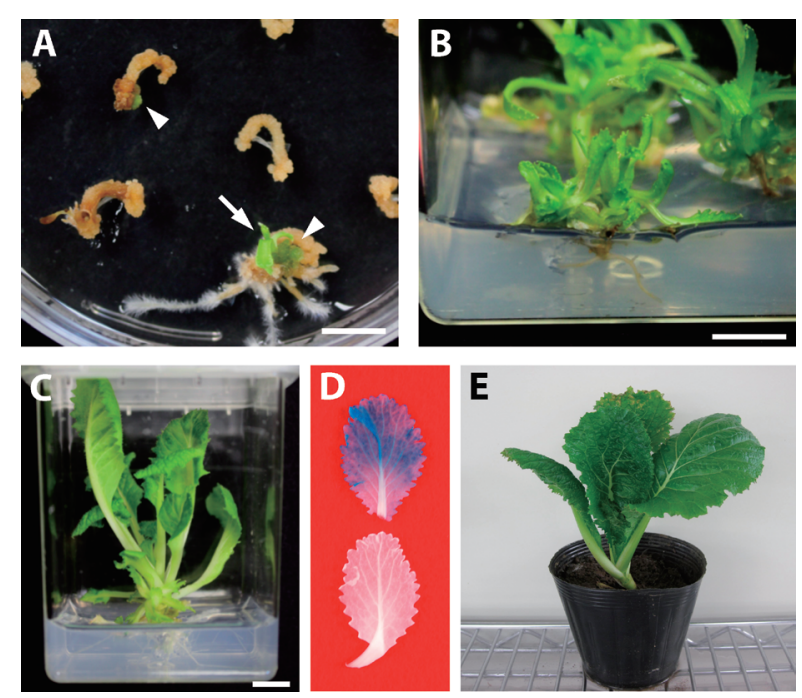

Figure 3. Agrobacterium-mediated transformation of Chinese cabbage cv. Chihiri 70 at different stages of in vitro regeneration and screening of transformed plants. (A) Appearance of green shoots (arrow) and green calli (arrow head) from hypocotyl segments on BCR medium containing $0.25 \mathrm{mgl}^{-1}$ bispyribac sodium (BS). (B) Regeneration of multiple shoots from green callus on shoot maturation medium containing $0.25 \mathrm{mgl}^{-1} \mathrm{BS}$. (C) Individual shoot in hormonefree MS media for elongation and rooting. (D) Histochemical GUS assay of transgenic (upper) and nontransformed (lower) leaves. (E) Potted plant in the greenhouse. Bars, $1 \mathrm{~cm}$.

solution unlike leaves of untransformed plants (Figure 3D). Full-grown rooted plantlets were transferred to pots in the greenhouse (Figure 3E). The GUS gene was detected by DNA gel blot analysis in all elongated plants (Figure 4A, Table 3). The transformation frequencies of $1.2 \%$ and $1.1 \%$ were nearly the same with the BS and hygromycin selections, respectively. These frequencies with both the mutated ALS gene and hpt gene were approximately 1.6-2.7\% (Zhang et al. 2000) and 1.1\% (Kuginuki et al. 2001) reported using conventional methods with the nptII gene in the Japanese cultivar of heading Chinese cabbage. Ours is the first report to show that the mutated ALS and hpt genes are available as selectable markers for the Japanese cultivar of Chinese cabbage.

When Ryokurei explants were transferred to BCR media containing selection agents, most of the explants showed green callus or adventitious shoot formation in one or both of the cut ends of hypocotyls within 4 weeks. Resistant plantlets were obtained after 2 months on shoot maturation medium. Transformation frequencies, based on DNA gel blot analysis, were $13.9 \%$ for BS selection and $15.0 \%$ for hygromycin selection. These frequencies were higher than the previously reported $10 \%$ transformation frequency based on acquisition of kanamycin-resistant shoots (Kuginuki et al. 2001) and $4.3 \%$ transformation frequency using GUS (Mets et al. 1995).

With both Chihiri 70 and Ryokurei, the proportions
A

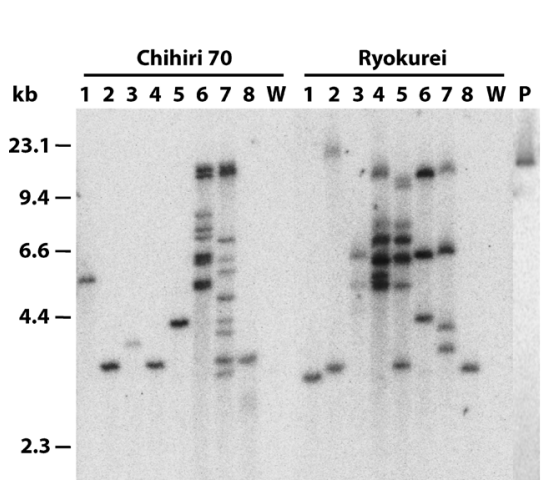

B

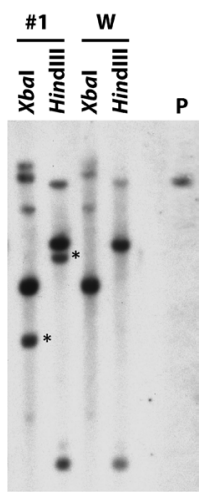

Figure 4. DNA gel blot analysis of transgenic Chinese cabbage cv. Chihiri 70 and broccoli cv. Ryokurei plants using BS as the selection agent. (A) HindIII-digested genomic DNA from a wild-type plant (W), eight primary transgenic Chihiri 70 plants, and eight primary transgenic Ryokurei plants transformed with pSMAA-35S:GUS were hybridized with a ${ }^{32} \mathrm{P}$-labeled GUS-specific probe. Lane P, SacI-digested pSMAA-35S:GUS (50 pg). (B) XbaI- or HindIII-digested genomic DNAs from a primary transgenic Chihiri 70 plant transformed with pSMAA-BoA3:Bogai (\#1) and from a wild-type plant (W) were hybridized with a ${ }^{32} \mathrm{P}$-labeled Bogai-specific probe. Lane P, SacI-digested pSMAA-BoA3:Bogai (50 pg). Asterisks indicate bands derived from the transgene.

of escapes (no elongated shoots on selection medium or GUS-negative shoots by DNA gel blot analysis) in the BS selection were lower (27.7\% and $14.4 \%$, respectively) than in the hygromycin selection $(42.9 \%$ and $29.8 \%$, respectively). Furthermore, the number of green calli in the Ryokurei BS selection was more than half of the hygromycin selection, despite equal transformation frequencies. These results indicated that selection on BS reduces escape, thereby contributing to transformation efficiency.

\section{Genetic analysis of transgenic plants}

To confirm the stable integration of the transgenes into the plant genomes, DNA gel blot analysis was performed on all elongated plants on MS medium containing BS using a GUS probe. Figure 4A shows DNA gel blot analysis of representative transgenic plants transformed with pSMAA-35S:GUS. The GUS probe hybridized to digested DNA from all BS-resistant plants, but not to digested DNA from the wild-type plant (Figure 4A, Table 3). These results indicate that the transgene is almost certainly incorporated into the plant genome in the elongated plants obtained by BS selection. The copy number of the transgene varied from 1 to 10 , although there were no relationships between the Brassica species or selective agent and the copy number.

We attempted to introduce a useful trait, such as male sterility, into Chinese cabbage using the BrmALS3 selectable marker system. pSMAA-BoA3:Bogai (Figure 1C) contained the stamen-specific promoter (BoA3) driving the gibberellin insensitive (Bogai) gene and the 
Rubisco gene terminator. This Bogai cassette, derived from the broccoli cv. Ryokurei, confers male sterility on A. thaliana (Konagaya et al. 2008) and broccoli (Konagaya et al. in preparation). Chihiri 70 hypocotyl explants were inoculated with Agrobacterium harboring pSMAA-BoA3:Bogai and selected on BS-supplemented medium as described above. The transformation frequency was $1.0 \%$, approximately equal to the transformation frequency with pSMAA-35S:GUS (Table 3). DNA gel blot analysis of line \#1 transformed with pSMAA-BoA3:Bogai is shown in Figure 4B. Although several bands were detected in the wild type because of hybridization of the Bogai probe to the endogenous GAI gene, a new band was detected in line \#1 (Figure $4 \mathrm{~B})$. As a result, we considered the transgene in line \#1 to be a single copy. However the pollen of the vernalized transformant (line \#1) was observed (data not shown). Since the recovery of male sterile lines from BoA3:Bogai transformants was low in Arabidopsis and broccoli (Konagaya et al. 2008; Konagaya et al. in preparation), obtaining a male sterile line using BoA3:Bogai may require production of many independent transformants and selection of them. Transgene inheritance was confirmed in $\mathrm{T}_{1}$-generation Chinese cabbage plants using genomic PCR analysis and PCR-RFLP. Amplification of Bogai was observed in the $\mathrm{T}_{1}$ generation plants (Figure $5 \mathrm{~A})$, indicating successful transgene inheritance in the next generation. In addition, PCR-RPLP showed that the BrmALS3 gene was also inherited in Bogai $\mathrm{T}_{1}$ progeny (Supplemental Figure S2). The positive: negative segregation ratios fitted the expected ratios of $3: 1$ at a probability level of $5 \%\left(\chi^{2}=0.22, p=0.64\right)$ by the chisquared test, suggesting that the transgenes were inherited as a single locus and corresponding to the DNA gel blot analysis (Figure 4B).

\section{Herbicide tolerance in $T_{1}$ progeny}

To confirm herbicide resistance in $\mathrm{T}_{1}$ progeny with the BrmALS3 gene, we treated $\mathrm{T}_{1}$ Chihiri 70 plantlets with a BS dilution series $\left(0,0.5,1.0,6.3,25.0\right.$, and $50.0 \mathrm{~g}$ a.i. $\left.\mathrm{ha}^{-1}\right)$ in preliminary examination. We found that $25 \mathrm{~g}$ a.i. $\mathrm{ha}^{-1}$ was an appropriate concentration that completely killed non-transgenic Chihiri 70. After 2 weeks, the treated leaves of the Bogai intact progeny (Figure 5B, \#1-1) were alive and green, whereas the leaves of the control wildtype plants and the Bogai-deleted progeny (Figure 5B, $\# 1-4)$ turned brown and gradually died. These results suggested that the BrmALS3 gene could be introduced into Chinese cabbage as a selectable marker gene and that transgenic Chinese cabbage could regenerate through BS selective culturing.

\section{Conclusions}

The transformation efficiency of Chinese cabbage
A

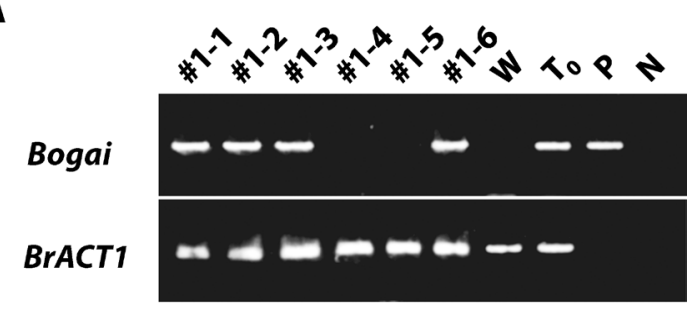

B

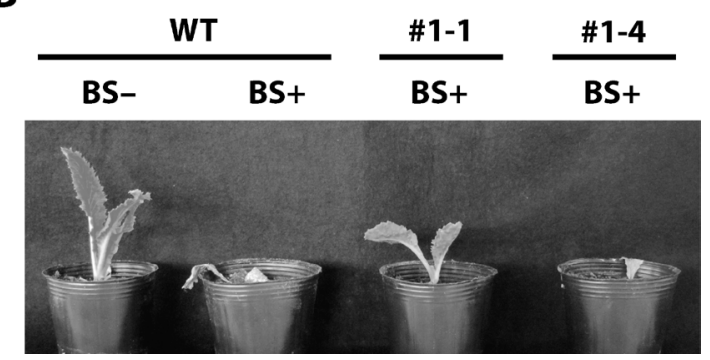

Figure 5. Genomic PCR analysis (A) and BS resistance (B) of $\mathrm{T}_{1}$ plants from pSMAA-BoA3:Bogai transformants. (A) Upper and lower panels show the PCR results obtained using Bogai-specific primers (Figure $1 ; 1.9 \mathrm{~kb})$ and the actin gene $(B r A C T 1,0.5 \mathrm{~kb})$, respectively. The $B r A C T 1$-specific primer was used to verify the quality of the genomic DNA samples. Lanes \#1-1-\#1-6, independent $T_{1}$ progeny from line \#1; Lane $\mathrm{W}$, wild-type plant; Lane $\mathrm{T}_{0}$, line \#1 primary transformant; Lane $\mathrm{P}$, pSMAA-BoA3:Bogai (positive control); Lane N, without template DNA (negative control). (B) BS sensitivities after two weeks of treatment (25 ga.i. ha ${ }^{-1}$ ). The $\mathrm{T}_{1}$ progeny that inherited the Bogai gene (\#1-1) exhibited vigorous growth under BS treatment, whereas the WT and the $\mathrm{T}_{1}$ progeny that had lost the insertion of pSMAA-BoA3:Bogai (\#14) were killed. BS+ and BS - indicate treatment with or without BS, respectively.

was lower than that of broccoli, despite a higher Agrobacterium infection efficiency (Figure 2). This result indicates that improvement of regeneration and selection efficiency should be required for developing more effective transformation system in Chinese cabbage. Reliable and efficient transformation system should contribute to produce novel varieties and to promote basic research with utilizing information of genome sequence of Chinese cabbage (Wang et al. 2011). Here, we have shown that the BrmALS3 gene can be used as an effective selectable marker in Chinese cabbage and broccoli. Cisgenesis is new plant breeding techniques (Lusser et al. 2012) based on the use of natural genes (cisgenes) from the target plant itself or from a cross compatible species. This report demonstrates for the first time that a mutated $A L S$ gene under the control of a promoter and terminator derived from the cisgene is available as a selectable marker for Agrobacteriummediated transformation in Brassica species. Selectable markers derived from familiar food plant genes may help promote public acceptance of GM crops. Furthermore, use of cisgenes may allow for exceptions or mitigations of food safety regulations if the European Food Safety Authority (EFSA) Panel concludes that any hazards 
associated with cisgenic plants are similar to those associated with conventionally bred plants (EFSA Journal 2012; 10(2): 2561; http://www.efsa.europa.eu/ en/efsajournal/pub/2561.htm). The transformation techniques based on cisgenesis in this study will be informative to address both environmental and consumer concerns for GM agriculture.

\section{Acknowledgments}

This work was supported by the Assurance of the Safe Use of Genetically Modified Organisms (The Ministry of Agriculture, Forestry and Fisheries of Japan). We thank Dr. Hiroaki Ichikawa (National Institute of Agrobiological Sciences) for providing pSMAH628 $\Omega-M 2 G U S$ and Aya Sugai, Junko Shioda, and Dr. Yoshihiko Nanasato for their technical assistance with the plant transformation. The authors would like to thank Enago (www. enago.jp) for the English language review.

\section{References}

Abe H, Narusaka Y, Sasaki I, Hatakeyama K, Shin-I S, Narusaka M, Fukami-Kobayashi K, Matsumoto S, Kobayashi M (2011) Development of full-length cDNAs from Chinese cabbage (Brassica rapa Subsp. pekinensis) and identification of marker genes for defence response. DNA Res 18: 277-289

Akama K, Shiraishi H, Ohta S, Nakamura K, Okada K, Shimura Y (1992) Efficient transformation of Arabidopsis thaliana: comparison of the efficiencies with various organs, plant ecotypes and Agrobacterium strains. Plant Cell Rep 12: 7-11

An G, Ebert PR, Mitra A, Ha SB(1988) Binary vectors. In: Gelvin SB, Schilpeoort RA (eds) Plant molecular biology manual. Kluwer, Dordrecht, pp 1-19

Andersson M, Trifonova A, Andersson AB, Johansson M, Bülow L, Hofvander P (2003) A novel selection system for potato transformation using a mutated AHAS gene. Plant Cell Rep 22: 261-267

Ando S, Asano T, Tsushima S, Kamachi S, Hagio T, Tabei Y (2005) Changes in gene expression of putative isopentenyltransferase during clubroot development in Chinese cabbage (Brassica rapa L.). Physiol Mol Plant Pathol 67: 59-67

Bagheri H (2009) Genetic analysis of breeding-related traits in Brassica rapa. Dissertation, Wageningen University

Cardoza V, Stewart CN Jr (2004) Brassica biotechnology: recent progress in cellular and molecular biology. In Vitro Cell Dev Biol Plant 40: 542-551

Chen LFO, Hwang JY, Charng YY, Sun CW, Yang SF (2001) Transformation of broccoli (Brassica oleracea var. italica) with isopentenyltransferase gene via Agrobacterium tumefaciens for post-harvest yellowing retardation. Mol Breed 7: 243-257

Cho HS, Cao J, Ren JP, Earle ED (2001) Control of Lepidopteran insect pests in transgenic Chinese cabbage (Brassica rapa ssp. pekinensis) transformed with a synthetic Bacillus thuringiensis cry1C gene. Plant Cell Rep 20: 1-7

Gamborg OL, Miller RA, Ojima K (1968) Nutrient requirements of suspension cultures of soybean root cells. Exp Cell Res 50: 151-158

Jefferson RA (1987) Assaying chimeric genes in plants: the GUS gene fusion system. Plant Mol Biol Rep 5: 387-405

Jun SI, Kwon SY, Paek KY, Paek KH (1995) Agrobacteriummediated transformation and regeneration of fertile transgenic plants of Chinese cabbage (Brassica campestris ssp. pekinensis $\mathrm{cv}$. 'spring flavor'). Plant Cell Rep 14: 620-625

Kawai K, Kaku K, Izawa N, Shimizu M, Kobayashi H, Shimizu T (2010) Transformation of Arabidopsis by mutated acetolactate synthase genes from rice and Arabidopsis that confer specific resistance to pyrimidinylcarboxylate-type ALS inhibitors. Plant Biotechnol 27: 75-84

Konagaya K, Ando S, Kamachi S, Tsuda M, Tabei Y (2008) Efficient production of genetically engineered, male-sterile Arabidopsis thaliana using anther-specific promoters and genes derived from Brassica oleracea and B. rapa. Plant Cell Rep 27: 1741-1754

Koncz C, Schell J (1986) The promoter of TL-DNA gene 5 controls the tissue specific expression of chimaeric genes carried by a novel type of Agrobacterium binary vector. Mol Gen Genet 204: 383-396

Kuginuki Y, Tsukazaki H (2001) Regeneration ability and Agrobacterium-mediated transformation of different cultivars in Brassica oleracea L. and B. rapa L. (syn. B. campestris L.). J Jpn Soc Hort Sci 70: 682-690

Lee MK, Kim HS, Kim JS, Kim SH, Park YD (2004) Agrobacteriummediated transformation system for large-scale production of transgenic Chinese cabbage (Brassica rapa L. ssp. pekinensis) plants for insertional mutagenesis. J Plant Biol 47: 300-306

Lim C, Kim S, Choi Y, Park YD, Kim SU, Sung SK (2007) Utilization of the bar gene to develop an efficient method for detection of the pollen-mediated gene flow in Chinese cabbage (Brassica rapa spp. pekinensis). Plant Biotechnol Rep 1: 19-25

Lusser M, Parisi C, Plan D, Rodríguez-Cerezo E (2012) Deployment of new biotechnologies in plant breeding. Nat Biotechnol 30: 231-239

Mazur BJ, Falco SC (1989) The development of herbicide resistant crops. Annu Rev Plant Physiol Plant Mol Biol 40: 441-470

Metz TD, Dixit R, Earle ED (1995) Agrobacterium tumefaciensmediated transformation of broccoli (Brassica oleracea var. italica) and cabbage (B. oleracea var. capitata). Plant Cell Rep 15: 287-292

Min BW, Cho YN, Song MJ, Noh TK, Kim BK, Chae WK, Park YS, Choi YD, Harn CH (2007) Successful genetic transformation of Chinese cabbage using phosphomannose isomerase as a selection marker. Plant Cell Rep 26: 337-344

Murashige T, Skoog F (1962) A revised medium for rapid growth and bioassay with tobacco tissue culture. Physiol Plant 15: 472-493

Nanasato Y, Konagaya K, Okuzaki A, Tsuda M, Tabei Y (2011) Agrobacterium-mediated transformation of kabocha squash (Cucurbita moschata Duch) induced by wounding with aluminum borate whiskers. Plant Cell Rep 30: 1455-1464

Nanasato Y, Konagaya K, Okuzaki A, Tsuda M, Tabei Y (2012) Improvement of Agrobacterium-mediated transformation of cucumber (Cucumis sativus L.) by combination of vacuum infiltration and co-cultivation on filter paper wicks. Plant Biotech Rep, DOI 10.1007/s11816-012-0260-1

Narasimhulu SB, Chopra VL (1988) Species specific shoot regeneration response of cotyledonary explants of Brassicas. Plant Cell Rep 7: 104-106

Ogawa T, Kawahigashi H, Toki S, Handa H (2008) Efficient transformation of wheat by using a mutated rice acetolactate synthase gene as a selectable marker. Plant Cell Rep 27: 1325-1331

Ohta S, Mita S, Hattori T, Nakamura K (1990) Construction and expression in tobacco (Nicotiana tabacum) of a betaglucuronidase (GUS) reporter gene containing an intron within 
the coding sequence. Plant Cell Physiol 31: 805-813

Okuzaki A, Shimizu T, Kaku K, Kawai K, Toriyama K (2007) A novel mutated acetolactate synthase gene conferring specific resistance to pyrimidinyl carboxy herbicides in rice. Plant $\mathrm{Mol}$ Biol 64: 219-224

Osakabe K, Endo M, Kawai K, Nishizawa Y, Ono K, Abe K, Ishikawa Y, Nakamura H, Ichikawa H, Nishimura S, Shimizu T, Toki S (2005) The mutant form of acetolactate synthase genomic DNA from rice is an efficient selectable marker for genetic transformation. Mol Breed 16: 313-320

Park BJ, Liu ZC, Kanno A, Kameya T (2005) Genetic improvement of Chinese cabbage for salt and drought tolerance by constitutive expression of a B. napus LEA gene. Plant Sci 169: 553-558

Poulsen G (1996) Genetic Transformation of Brassica. Plant Breed 115: 209-225

Rawat P, Ray K, Pental D, Burma PK (2008) Mutant acetolactate synthase gene conferring resistance to the herbicide "imazethapyr" is an efficient in vitro selection marker for genetic transformation of cotton. Curr Sci 95: 1454-1458

Ray K, Jagannath A, Gangwani SA, Burma PK, Pental D (2004) Mutant acetolactate synthase gene is an efficient in vitro selectable marker for the genetic transformation of Brassica juncea (oilseed mustard). J Plant Physiol 161: 1079-1083

Sambrook J, Russell DW(2001) Molecular cloning: a laboratory manual, 3rd edn. Cold Spring Harbor Laboratory, Cold Spring Harbor, New York

Shin J, Cho H, Chung YY, Park MC (2003) Transformation of rice OsMADS1 gene causes homeotic mutations in floral organs of Chinese cabbage (Brassica campestris). J Plant Biol 46: 46-51

Sparrow PAC, Goldsack CM, Østergaard L(2011) Transformation technology in the Brassicaceae. In: Schmidt R, Bancroft I (eds) Genetics and Genomics of the Brassicaceae. Springer, New York, pp 505-525

Suri SS, Saini ARK, Ramawat KG (2005) High frequency regeneration and Agrobacterium tumefaciens-mediated transformation of broccoli (Brassica oleracea var. italica). Euro
J Hort Sci 70: 71-78

Takasaki T, Hatakeyama K, Ojima K, Watanabe M, Toriyama K, Hinata K (1996) Effects of various factors (hormone combinations, genotypes and antibiotics) on shoot regeneration from cotyledon explants in Brassica rapa L. Plant Tissue Cult Lett 13: $177-180$

Takasaki T, Hatakeyama K, Ojima K, Watanabe M, Toriyama K, Hinata K (1997) Factors influencing Agrobacterium-mediated transformation of Brassica rapa L. Breed Sci 47: 127-136

Tougou M, Yamagishi N, Furutani N, Kaku K, Shimizu T, Takahata Y, Sakai J, Kanematsu S, Hidaka S (2009) The application of the mutated acetolactate synthase gene from rice as the selectable marker gene in the production of transgenic soybeans. Plant Cell Rep 28: 769-776

Vanjildorj E, Song SY, Yang ZH, Choi JE, Noh YS, Park S, Lim WJ, Cho KM, Yun HD, Lim YP (2009) Enhancement of tolerance to soft rot disease in the transgenic Chinese cabbage (Brassica rapa L. ssp. pekinensis) inbred line, Kenshin. Plant Cell Rep 28: 1581-1591

Wang X, Wang H, Wang J, Sun R, Wu J, Liu S, Bai Y, Mun JH, Bancroft I, Cheng F, et al. (2011) The genome of the mesopolyploid crop species Brassica rapa. Nat Genet 43: 1035-1039

Waterer D, Lee S, Scoles G, Keller W (2000) Field evaluation of herbicide-resistant transgenic broccoli. HortScience 35: 930-932

Zhang FL, Takahata Y, Xu JB (1998) Medium and genotype factors influencing shoot regeneration from cotyledonary explants of Chinese cabbage (Brassica campestris L. ssp. pekinensis). Plant Cell Rep 17: 780-786

Zhang FL, Takahata Y, Watanabe M, Xu JB (2000) Agrobacteriummediated transformation of cotyledonary explants of Chinese cabbage (Brassica campestris L. ssp. pekinensis). Plant Cell Rep 19: 569-575

Zhang Y, Yin X, Yang A, Li G, Zhang J (2005) Stability of inheritance of transgenes in maize (Zea mays L.) lines produced using different transformation methods. Euphytica 144: 11-22 

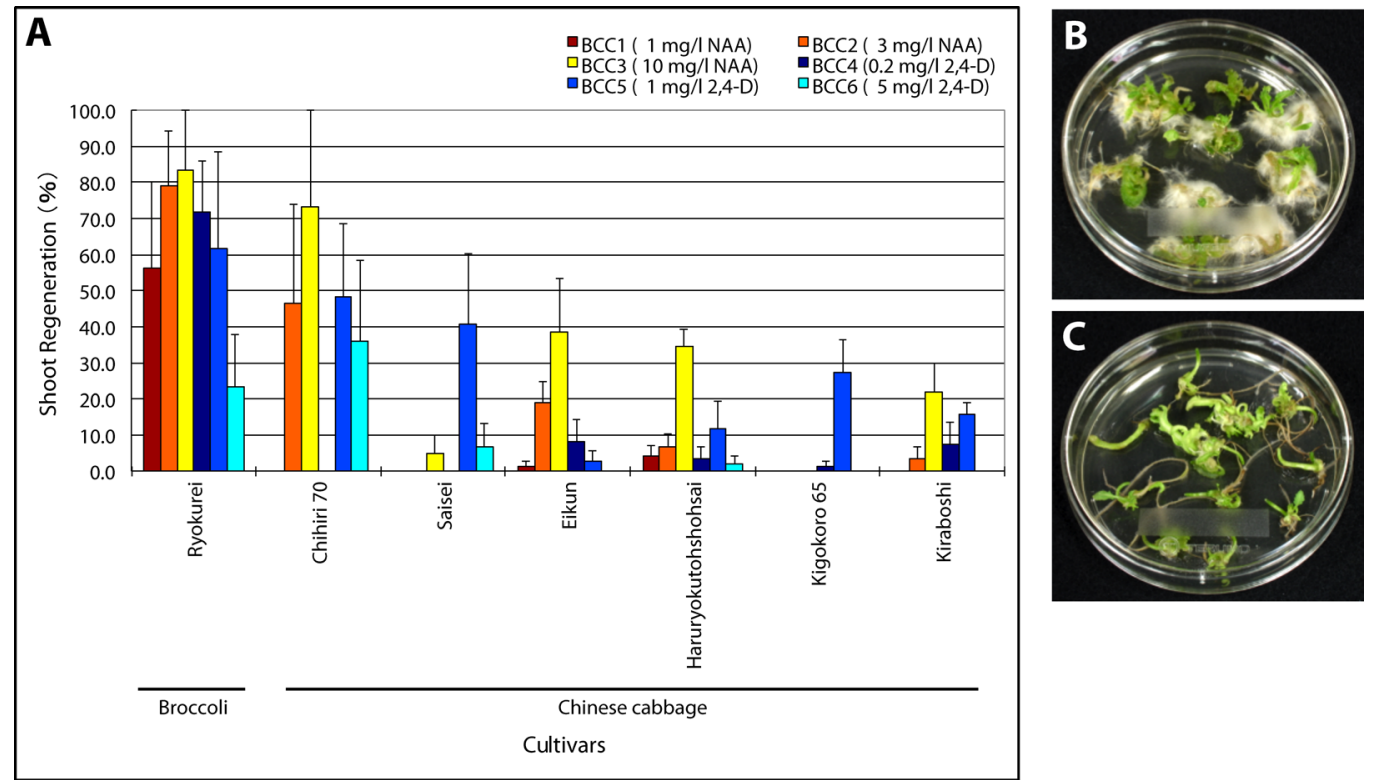

Supplemental Figure S1. (A) Shoot regeneration from hypocotyl explants of Chinese cabbage (B. rapa ssp. pekinensis) and broccoli (B. oleracea var. italica). Hypocotyl segments of 7-day-old seedlings were cultured on six different callus induction medium [B5 salts and vitamins (Gamborg et al. 1968), $1 \%$ sucrose, $0.4 \%$ gelrite, $\mathrm{pH} 5.8,1 \mathrm{mgl}^{-1}, 3 \mathrm{mgl}^{-1}$, or $10 \mathrm{mgl}^{-1} 1$-naphthaleneacetic acid (NAA), or $0.2 \mathrm{mgl}^{-1}, 1 \mathrm{mgl}^{-1}$, or $5 \mathrm{mgl}^{-1}$ 2,4-dichlorophenoxyacetic acid (2,4-D), corresponding to BCC1-6, respectively] for 2 weeks. The explants were transferred to shoot regeneration medium (BCR: B5 salts and vitamins, $3 \mathrm{mgl}^{-1}$ 6-benzylamino purine, $1 \mathrm{mgl}^{-1}$ zeatin, $10 \mathrm{mgl}^{-1} \mathrm{AgNO}_{3}, 1 \%$ sucrose, $0.4 \%$ gelrite, $\mathrm{pH}$ 5.8) and subsequently subcultured every 2 weeks. After 5 weeks, the numbers of explants forming adventitious shoots were counted. Data are from three replicates with 10 hypocotyl explants for each replicate. Bars represent standard errors of the means. (B, C) Shoots developing from hypocotyl explants of Chinese cabbage cv. Chihiri 70 (B) and broccoli cv. Ryokurei (C). Hypocotyl segments of Chihiri 70 and Ryokurei were cultured on BCC3 and BCC2 media, respectively, for 2 weeks and then cultured on BCR medium for 5 weeks.

A Wild-type ALS locus
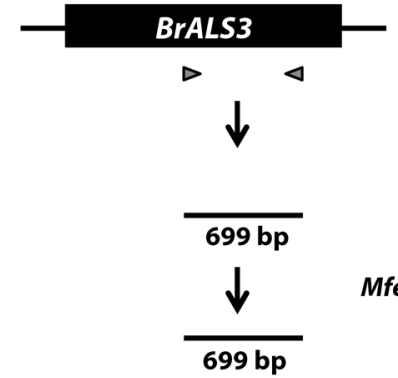

\section{Ectopically integrated} mutated $A L S$ locus

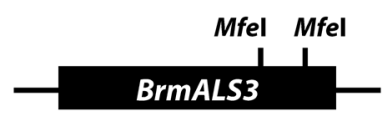

PCR

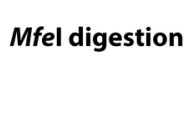

B

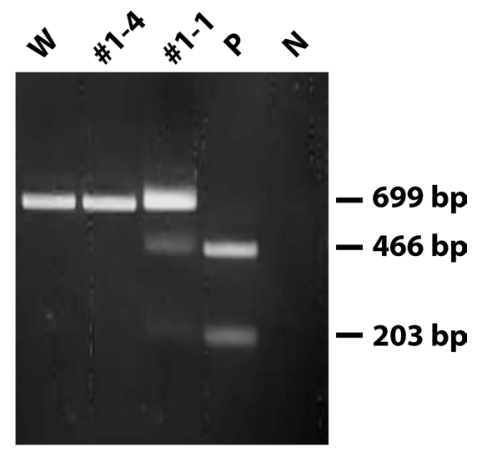

Supplemental Figure S2. (A) Schematic of the PCR-RFLP assay. Black boxes represent the ORFs of the ALS genes. Arrowheads represent the primer sets for BrALS3 and BrmALS3 detection. (B) PCR-RFLP assay of T1 progeny. MfeI-digested genomic PCR products were separated by $2 \%$ agarose gel electrophoresis. Lane W, wild type; Lanes \#1-4 and \#1-1, independent T1 progeny [\#1-4 and \#1-1 correspond to Bogai-lost/BS-sensitive and Bogaiinherited/BS-resistant progeny, respectively, in Figure 6]; Lane P, pSMAA-BoA3:Bogai (positive control); Lane N, without template DNA (negative control). 